\title{
Multi-color Joint Probability Statistics Model-based Object Tracking System
}

\author{
P. Palanichamy \\ Department of Mathematics, AMET University, Chennai, India
}

\begin{abstract}
Article Info
Article history:

Received Nov 21, 2017

Revised Jan 29, 2018

Accepted Feb 17, 2018

\section{Keywords:}

Camshaft

Multi-colour model

Probability statistics

Target tracking

ABSTRACT

For continuous target following under complex scene, an objective following calculation in light of multi-shading joint likelihood investigation model was introduced. The calculation embraced shading histogram to speak to the actual factual trademark with Camshaft standard and completed exploratory research in such angles as multichannel joint shading highlights measurements, projection delineate weighted preparing, the following window size and position ascertaining, calculation handling component of course. It utilised red, green, blue, tint, luminance channel shading as the objective watched attributes, and planned the computation technique given the likelihood measurement to recognise any shading focus from the compound scene. It likewise settled the counting method for following window size and position which adjusted the multi-shading model. Utilizing weighting projection outline strategy, the foundation obstruction around the objective potential territory was dispensed with. Finally, more reasonable joining judgment and the calculation cycle tenets were advanced. After the test accreditation, the ongoing execution and recognition proportion introduce a decent outcome.
\end{abstract}

Copyright $\odot 2018$ Institute of Advanced Engineering and Science. All rights reserved.

\section{Corresponding Author:}

P. Palanichamy,

Department of Mathematics,

AMET University, Chennai, India.

\section{INTRODUCTION}

Shading data is the best exemplification of the objective element data. The exhuming and utilisation of shading data has been a critical research course in many targets following calculations. As a general delegate, Camshaft [1] calculation utilised the shading histogram as the real model and followed the objective by finding the "centroid" of weighted guide iteratively [2]. This hypothesis gives necessary rules to the plan of shading following calculation. Be that as it may, the reliance of Camshaft traditional calculation on HSV shading model additionally confines the extent of utilisation of the math [3]. At the point when the shading model can't adjust to the progressions of target attributes, the execution of the calculation enormously diminished [4]. In this manner, numerous researchers at home and abroad start to research how to refresh and extend the depiction model of shading [5]. For the bungle between target shading model and reference layout brought about by time changes, Nummiaro proposed a versatile shading based calculation [6]. Image SuperResolution Using Wavelet Transformation Based Genetic Algorithm is presented in this paper [7]. Writing contemplated how to assemble Gaussian blend display on target and utilise the EM calculation to refresh it when the new perceptions arrived Robert T. In this paper also described in, Recognition and Tracking of Moving Object in Underwater Sonar Images [12]. In this article described and the Collins proposed the RGB straight combination strategy and upgraded the security of the shading qualities by shading mix. Writings and enhanced the mean move and Camshift calculation by building a multi-shading model for the objectives in various perspectives. In this paper also described in, Detection of glaucoma based on colour moments and SVM classifier using $\mathrm{k}$ means clustering [8]. 


\section{MULTI-COLOUR JOINT FEATURE DESCRIPTION}

\subsection{Multi-channel Data Acquisition}

Multi-channel is $\mathrm{R}, \mathrm{G}, \mathrm{B}, \mathrm{H}, \mathrm{Y}$ five shading channels. Joint utilisation of them can portray the external shading highlights all the more completely. R, G, B is the red, green, blue segments in RGB shading space. $\mathrm{Y}$ is the luminance portion in YUV shading space. $\mathrm{H}$ is the tint section in HSV shading space. Shading space is a three-dimensional organise framework. Each shading is communicated by a point. In RGB shading space, red, green and blue are the essential components. In YUV space, each shading has a luminance flag Y, and two chrominance signals $\mathrm{U}$ and V. The HSV space incorporates three segments: H, S, V. H speaks to tone, and $\mathrm{S}$ speaks to immersion and $\mathrm{V}$ speaks to shine. As appeared in Figure 1. The shade $\mathrm{H}$ is to depict the properties of high shading. The camshaft calculation is to utilise the $\mathrm{H}$ channel information to portray the objective qualities. In this paper also described in, Motion Estimation Search Algorithm Using New Cross Hexagon-Diamond Search Pattern [13].

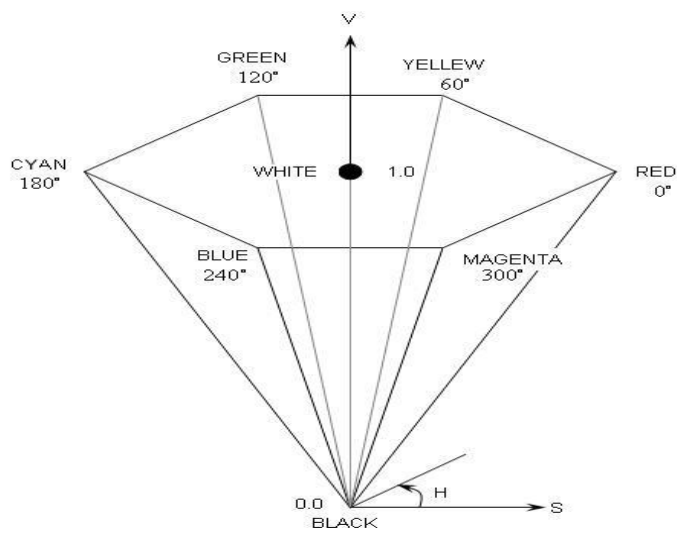

Figure 1. HSV Colour space

From an RGB colour format image, H, S, V components of each pixel can be gained by the following equations, in which $\mathrm{R}, \mathrm{G}$, and $\mathrm{B}$ values range from 0 to 1 :

$$
\begin{aligned}
& H= \begin{cases}H \times 60 & H^{\prime} \geq 0 \\
H \times 60+360 & H^{\prime}<0\end{cases} \\
& S=(V-\min (R, G, B)) / V \\
& V=\max (R, G, B) \\
& \operatorname{In}(1), \\
& H^{\prime}= \begin{cases}(G-B) /(S \times V) & V=R \\
2+(B-R) /(S \times V) & V=G \\
4+(R-G) /(S \times V) & V=B\end{cases}
\end{aligned}
$$

After this transformation, the hue information $\mathrm{H}$ ranges from $0^{\circ}$ to $360^{\circ} . \mathrm{S}$ and $\mathrm{V}$ range from 0 to 1. To facilitate the use of histogram analysis, we often adjust them to the range $[0,255]$. Then the data distributions of YHV channels can be shown in the Figure 2.

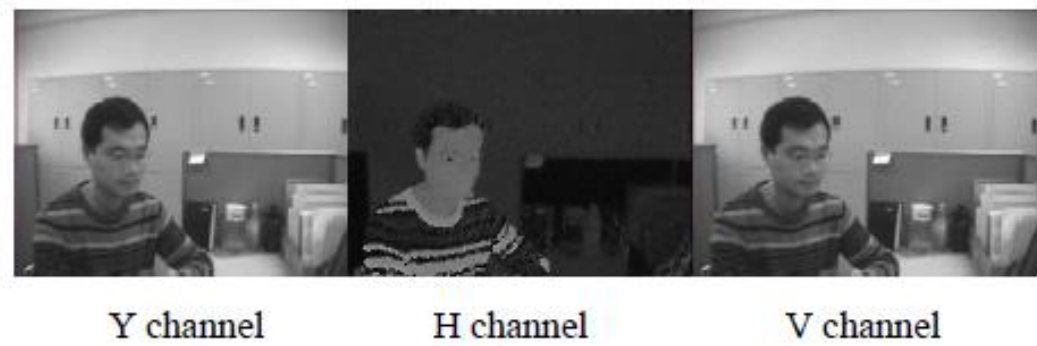

Figure 2. Data distribution in YHV channels 
From the image above, we can see that the V in HSV is similar to the Y in YUV, and they both describe the brightness of a picture. However, as the $\mathrm{V}$ has the loss of accuracy when transformed from [0,1] to [0, 255], we use the $\mathrm{Y}$ component as one of the standard channels. Its calculation equation is (5).

$$
Y=0.299 R+0.587 G+0.114 B
$$

\subsection{Quantification of Multi-Channel Data}

After getting R, G, B, H, Y five-channel information, we ought to evaluate each channel information to compute the likelihood dispersion in the measurable region of target attributes. The supposed evaluation is to partition the channel information into a few levels in $[0,255]$. Its motivation is to accomplish the best adjust of target recognition and adaptation to internal failure. Since the discovery is excessively delicate in 256-level, slight vacillations of light or different components can bring about the real station changes, then target likelihood turns out to be inaccurate, lastly focus following would come up short. In this paper also described in, Change Detection from Remotely Sensed Images Based on Stationary Wavelet Transform [10]. So we ought to partition the information into a few levels and keep the vacillation of target channel information inside a similar level. At that point, the adaptation to a non-critical failure of a framework made strides. Obviously, the division ought not to be too unpleasant. Something else, diverse information will be confounded in one same level if the external shading is near foundation. At that point, it could lessen the location execution of framework. As appeared in Figure 2, considering R, G, B, Y channels and H channel have distinctive smoothness, we partition R, G, B, Y channels into 51 levels and separation $\mathrm{H}$ channel into 17 levels. Each channel information is communicated as:

$$
D_{m}^{R}, D_{m}^{G}, D_{m}^{B}, D_{m}^{H}, D_{m}^{Y}, \text { where } \mathrm{m}=51, \mathrm{n}=17
$$

\subsection{Calculation of Joint Probability and Grey Projection}

The exact range of target attributes is an arrangement of pixels which is utilised to ascertain the multi-channel shading qualities of a target. This territory has a place with target following window. While introducing the calculation, the actual region is equivalent to target following window. In taking after computations, it characterises the arrangement of pixels which dark esteem is more noteworthy than eight as the actual range of target qualities inside the following window. At that point tally the information of each level of five channels and ascertain the real likelihood table. The probability of each channel level will be communicated as:

$$
\left\{\begin{array}{l}
P_{u}^{R}=D_{u}^{R} / \max \left(D_{u}^{R}\right)_{u=1 \ldots m}\left(\text { if } \max \left(D_{u}^{R}\right)=0, P_{u}^{R}=0\right) \\
P_{u}^{G}=D_{u}^{G} / \max \left(D_{u}^{G}\right)_{u=1 \ldots m}\left(\text { if } \max \left(D_{u}^{G}\right)=0, P_{u}^{G}=0\right) \\
P_{u}^{B}=D_{u}^{B} / \max \left(D_{u}^{B}\right)_{u=1 \ldots m}\left(\text { if } \max \left(D_{u}^{B}\right)=0, P_{u}^{B}=0\right) \\
P_{u}^{H}=D_{u}^{H} / \max \left(D_{u}^{H}\right)_{u=1 \ldots m}\left(\text { if } \max \left(D_{u}^{H}\right)=0, P_{u}^{H}=0\right) \\
P_{u}^{Y}=D_{u}^{Y} / \max \left(D_{u}^{Y}\right)_{u=1 \ldots n}\left(\text { if } \max \left(D_{u}^{Y}\right)=0, P_{u}^{Y}=0\right)
\end{array}\right.
$$

The joint target probability is defined as:

$$
P=\left(P_{u_{1}}^{R}+P_{u_{2}}^{G}+P_{u_{3}}^{B}+P_{u_{4}}^{H}+P_{u_{5}}^{Y}\right) / 5,{ }_{u_{x}=1 \ldots m(x=1,2,3,4), u 5=1 \ldots n}
$$

Target following window is a potential target rectangular range and additionally calculation window. The window is characterised physically at first and gotten by ascertaining later on. Taking after (6), we can compute the five channel look-into tables from pixel to likelihood, and afterwards, determine some pixel likelihood by (7). Base on hypothesis over, the calculation finds the five channel probability of a pixel in the objective following window, and figure the joint target likelihood $\mathrm{P}$ of this pixel. At that point, it changes the $\mathrm{P}$ to the range $[0,255]$ to get the dim likelihood estimation of this pixel and change every one of the pixels in the objective following window to get the risk dark projection guide of the target following region. Along these lines, we pick up multi-shading joint target attributes by the strategy for multi-shading joint likelihood insights show. In this paper also described in, reviewing the Effectivity Factor in Existing Techniques of Image Forensics [11].

\subsection{Procedure of Zone Weighted Projection}

Target following window is a potential target rectangle area, so the objective region is a subset of the target following window. While figuring the likelihood dim of the target following window as indicated by the present look-into table of target risk, we more often than not duplicate the dark of target following 
window with a calculate $\alpha$ request to lessen the foundation clamour. Esteem $\alpha$ is in the vicinity of 0 and 1 , and the nearer to the inside, the littler $\alpha$ is. As far as possible will rely on upon the test condition.

Considering the planned standard of weighting projection in a mean move, we devise a technique for weighted preparing called typical pivot proportion projection. It characterises $\mathrm{x} \mathrm{r}$ as the extent of the separation from pixel $\mathrm{Q}(\mathrm{x}, \mathrm{y})$ to the inside and the separation from $\mathrm{Q}$ to $\mathrm{X}$ pivot in $\mathrm{X}$. Additionally, it characterises $\mathrm{yr}$ as the extent of the separation from $\mathrm{Q}$ to the middle and the separation from $\mathrm{Q}$ to $\mathrm{Y}$ in $\mathrm{Y}$ :

$$
\left\{\begin{array}{l}
r_{x}=\frac{\left|x-x_{o}\right|}{L_{x}} \\
r_{y}=\frac{\left|y-y_{o}\right|}{L_{y}}
\end{array}\right.
$$

Define $\alpha$ as the weighted factor of the pixel Q:

$$
\alpha=\frac{1-2 r_{x}+1-2 r_{y}}{2}+b,(\text { if } \alpha>1, \alpha=1)
$$

Where $\mathrm{b}$ is the adjustment factor between 0 and 1 , and it is 0.5 in this paper.

Through correlation, we find that the weighting preparing can undoubtedly dispose of the commotion obstruction of the rear window edge. Be that as it may, over-weighting will likewise influence the extent of focus in the following window. So it's imperative to discover the adjust point for the level of weighting. Calculate $\mathrm{b}$ is intended for this issue.
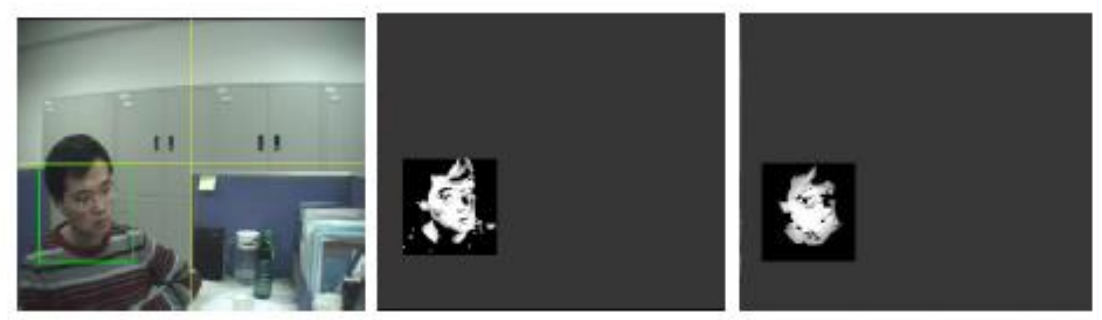

Figure 3. Reflect the effect analysis of weighted projection

\section{OUTLINE OF CALCULATION HANDLING INSTRUMENT}

After the over three sections are finished, we'll describe the processing device of the calculation next. With a specific end goal to decrease the computational load and enhance the registering exactness, limited iterative circle component in light of target window will be utilised as a part of the calculation. Figure 4 depicts the entire procedure. From Figure 4, the whole process can be communicated that right off the bat input the five-channel picture information and ascertain the joint likelihood look-into table in the objective attributes factual range, then change every pixel in the following window to get the projection of risk dark as per the look-into table, next pick up the places of target and window to meet to the objective centroid through limited iterative operations and modify the measure of window, and after that figure the actual qualities measurable territory and enter the following action. 


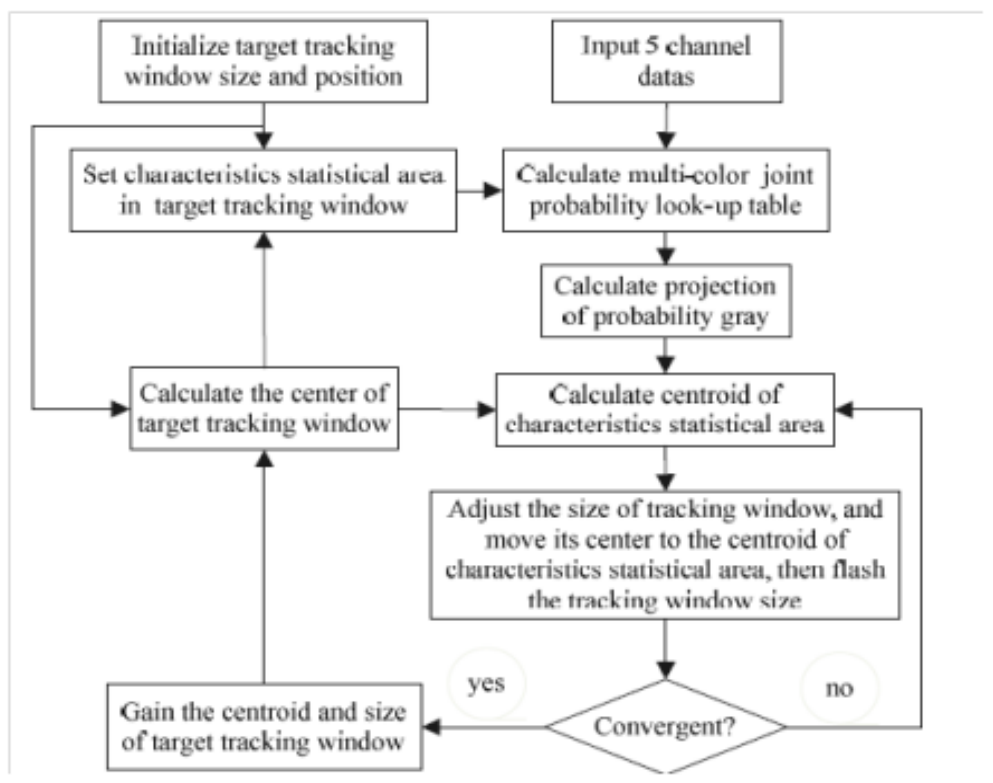

Figure 4. Flowchart

\section{JOINT-CHANNEL PERFORMANCE ANALYSIS}

Joint-channel enhances the expressive qualities of a target and improves the actual recognition ability of calculation. As appeared in Figure 2, from visual perception, the physical attributes portrayal of $\mathrm{H}-$ channel which Camshift depends on is not as rich as that of another channel.

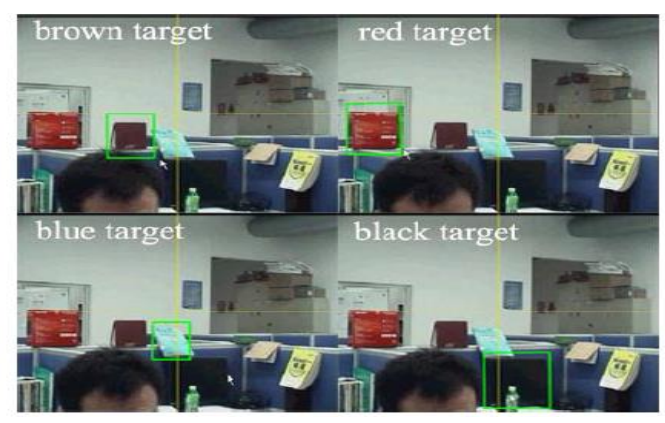

Figure 5. Target tracking for different colour

It demonstrates the identification impacts of the calculation for various shading targets. It means to check the high location ability of multi-channel for different hues. Be that as it may, Camshift calculation is invalid for the site of blue and deep focus in Figure 5. Blue and dark shading is not unmistakable in $\mathrm{H}$ channel.

\section{CONCLUSION}

An objective following calculation is given multi-shading joint likelihood examination model was proposed in this paper. It made some important investigations on the uncovering of target multi-shading data. In this article also described in, Fuzzy Region Merging using Fuzzy Similarity Measurement on Image Segmentation [9]. In particular, some new involutions were displayed on shading highlight show, zone weighted projection, and following window figuring. Tests ensured the excellent execution of the multishading model in Complex Scene. Be that as it may, a few points of interest ought to be enhanced later on. The most efficient method to streamline the joint system of multi-shading utilising the relations among the five channels would be a critical substance of our subsequent research. 


\section{REFERENCES}

[1] Bradski GR. Computer Vision Face Tracking as a Component of a Perceptual User Interface. In Proc. of the IEEE Workshop Applications of Computer Vision.1998; 214-219.

[2] Nummiaro K, Koller-Meier E, Van Gool L. An adaptive colour-based particle filter. Image and vision computing, 2003; 21(1): 99-110.

[3] Zhou SK, Chellappa R, Moghaddam B. Visual tracking and recognition using appearance-adaptive models in particle filters. IEEE Transactions on Image Processing. 2004; 13(11): 1491-1506.

[4] Leichter I, Lindenbaum M, Rivlin E. Mean-shift tracking with multiple reference colour histograms. Computer Vision and Image Understanding. 2010; 114(3): 400-408.

[5] Zuo J, Liang Y, Pan Q, Zhao CH, Zhang HC. Camshift tracker based on multiple colour distribution models. Acta Automatica Sinica. 2008; 34(7): 736-742.

[6] WANG Q, JIANG SH, ZHANG JQ, HU B. An Approach to Improve the Performance of Mean-shift Tracking Algorithm. Journal of Fudan University (Natural Science). 2007; 46(1): 85-90.

[7] Panda SS, Jena G. Image Super-Resolution Using Wavelet Transformation Based Genetic Algorithm. In Computational Intelligence in Data Mining. Springer India. 2016; 2: 355-361.

[8] Surendiran J, Saravanan SV, manivannan K. Detection of glaucoma based on colour moments and SVM classifier using k means clustering, International Journal of Pharmacy and Technology. 2016; 8(3): 16139-16148.

[9] Wawan Gunawan, Agus Zainal Arifin. Fuzzy Region Merging using Fuzzy Similarity Measurement on Image Segmentation. International Journal of Electrical and Computer Engineering (IJECE). 2017; 7(6): 3402-3410.

[10] Abhishek Sharma, Tarun Gulati. Change Detection from Remotely Sensed Images Based on Stationary Wavelet Transform. International Journal of Electrical and Computer Engineering (IJECE). 2017; 7(6): 3395-3401.

[11] Shashidhar TM, Ramesh KB. Reviewing the Effectivity Factor in Existing Techniques of Image Forensics. International Jorunal of Electrical and Computer Engineering (IJECE). 2017; 7(6): 3558-3569.

[12] S.Karthik, V.Annapoorani, S.Dineshkumar. Recognition and Tracking of Moving Object in Underwater Sonar Images. International Journal of MC Square Scientific Research (IJMSR). 2016; 8(1):93-98.

[13] Rajavelu T. Motion Estimation Search Algorithm Using New Cross Hexagon-Diamond Search Pattern. International Journal of MC Square Scientific Research (IJMSR). 2015; 7(1):104-111. 